Abstract ID: 202

Non-clinical

POSTER

\title{
Quantitative Evaluation of Effectiveness of Hospital Mesra Ibadah Course: A Pre-Post Study
}

Kow Ren $\mathrm{Yi}^{1}$, Mohd Jumaidi Md Hashim², Anas Nazhar ${ }^{2}$, Ed Simor Khan Mor Japar Khan ${ }^{1}$, Low Chooi Leng ${ }^{3}$

${ }^{1}$ Department of Orthopaedic Surgery, International Islamic University Malaysia

${ }^{2}$ Department of Religious Affairs, Hospital Tengku Ampuan Afzan, Kuantan Pahang

${ }^{3}$ Department of Radiology, Hospital Tengku Ampuan Afzan, Kuantan Pahang.

Introduction: Solat or prayer, as one of the five pillars of Islam, and it is associated with bio-psycho-social benefits in Muslim patients. Â Many Muslim patients neglected solat while being hospitalized as they are unaware of the convenience (rukhsoh) available for them. Ibadah Friendly Hospital Courses have been conducted in different states of Malaysia to impart knowledge to the hospital staff who can in turn educate their patients. This study aims to construct a content-validated assessment tool and to assess the effectiveness of a state-level Hospital Mesra Ibadah course. Materials and methods: A self-administered questionnaire was constructed and content-validated by a panel of three experts (two religious teachers and one consultant spine surgeon). All 15 questions achieved item-level content validity index (I-CVI) of 1.00 after two rounds of validation. The questionnaires were distributed to participants of a state-level Hospital Mesra Ibadah course to compare the participants' pre-course test score and post-course test score. Results: A total of 88 participants (48.9\%) were included in this study. There was a significant difference in the pre-course test mean score and post-course test mean score among the participants. There was also a significant reduction of unsure answer after the course. There was no significant association found between the gender, place of working and occupations with the pre-post test score difference. Conclusion: This study demonstrates that the Hospital Mesra Ibadah course is effective in imparting as well as consolidating the knowledge among participants, hence it should be routinely organized to benefit more participants. 